OPEN ACCESS

Edited by:

Tymon Zielinski,

Polish Academy of Sciences (PAS),

Poland

Reviewed by:

Marcus Geoffrey Haward

University of Tasmania, Australia

Elizabeth De Santo,

Franklin \& Marshall College,

United States

*Correspondence:

Elizabeth D. Hetherington ehetheri@ucsd.edu

Specialty section:

This article was submitted to Marine Affairs and Policy,

a section of the journal

Frontiers in Marine Science

Received: 24 February 2020

Accepted: 12 May 2020

Published: 05 June 2020

Citation:

Hetherington ED and Phillips AA

(2020) A Scientist's Guide

for Engaging in Policy

in the United States.

Front. Mar. Sci. 7:409.

doi: 10.3389/fmars.2020.00409

\section{A Scientist's Guide for Engaging in Policy in the United States}

\author{
Elizabeth D. Hetherington ${ }^{1 *}$ and Alexandra A. Phillips ${ }^{2}$ \\ 1 Integrative Oceanography Division, Scripps Institution of Oceanography, University of California, San Diego, La Jolla, CA, \\ United States, ${ }^{2}$ Geological and Planetary Sciences Division, California Institute of Technology, Pasadena, CA, United States
}

Scientific research and expertise play a critical role in informing legislative decisions and guiding effective policy. However, significant communication gaps persist between scientists and policymakers. While interest in science policy among researchers has substantially increased in recent decades, traditional academic and research careers rarely provide formal training or exposure to the inner workings of government, public policy, or communicating scientific findings to broad audiences. Here, we offer 10 practical steps for scientists who want to engage in science policy efforts, with a focus on state and federal policy in the United States. We first include a primer to government structure and tailoring science communication for a policymaker audience. We then provide action-oriented steps that focus on arranging and successfully navigating meetings with government officials. Finally, we suggest structural steps in academia that would provide resources and support for students, researchers, and faculty who are interested in policy. We offer our perspective, as early-career marine scientists who have participated in policy discussions at state and federal levels and through the American Geophysical Union's "Voices for Science" program. This guide offers potential pathways for engagement in science policy, and provides researchers with tangible actions to effectively reach stakeholders. Lastly, we hope to activate further conversations on best practices for policy engagement, particularly for researchers interested in careers at the science policy interface.

Keywords: science policy, government relations, policy engagement, science advocacy, United States policy

\section{INTRODUCTION}

Scientists are increasingly motivated to engage in science policy, either through communicating scientific results to policymakers or science-based advocacy (Baron, 2016; Hutchings and Stenseth, 2016). Many scientists believe they should engage with policymakers and play a role in shaping public policy, especially when policy issues or legislation directly relate to science (e.g., stem cell research; Besley and Nisbet, 2013). Policymakers and media outlets often rely on the expertise of scientists for interviews, testifying in congressional hearings, or addressing the general public on policy issues related to their research. However, while interest in policy has grown within the scientific community, large gaps in communication and engagement persist between scientists and policymakers.

Previous studies have reviewed the numerous barriers that contribute to the science-policy divide (e.g., Bertuol-Garcia et al., 2018). These barriers include, but are not limited to, scientists' questioning their own competence or expertise, believing their research is too complicated, 
narrowly-focused, and perhaps not relevant to larger policy discussions (Poliakoff and Webb, 2007; Singh et al., 2014). Some scientists are reluctant to engage in policy efforts because they are concerned about the politicization of science and blurring lines between acting as a knowledge broker versus an advocate (Weingart, 1999; Miller, 2009; Gluckman, 2014). Scientists and policymakers often have different motivations, goals, and objectives, which may limit collaboration or engagement between sectors. Researchers are also time limited and academic institutions often do not reward community related outreach activities (Singh et al., 2019), which may limit scientists' abilities to engage in policy outreach. Lastly, traditional academic pathways provide little training in science policy, communication, disseminating research to broad audiences, or using science to inform policy. Therefore, this lack of training on how to effectively engage in policy may be a barrier that limits scientists' participation. To bridge this gap, we focus specifically on how scientists can engage in policy, rather than if, when, or why scientists should engage.

Our primary objective is to create a guide for scientists who are interested in participating in policy but lack the training, practice, or resources to begin. The secondary objective is to begin a larger conversation about science policy engagement and best practices for scientists to take part in policy actions that relate to their expertise or field of study. We recognize that there are many pathways to engage in science policy, and the most effective actions may differ between countries with different governments and processes for enacting legislation. We specifically focus on 10 tangible actions to engage in science policy at local and federal levels in the United States and provide pertinent resources to do so. While we focus on U.S. policy, many of the steps are broadly relevant and we hope this framework will be adapted and edited to address science policy initiatives at different scales (local, regional, national, international).

\section{STEP 1: LEARN HOW SCIENCE POLICY IS ENACTED}

Science policy is an extensive international field encompassing collaborations between government agencies and nongovernment organizations and research scientists from various sectors (Etsy and Ivanova, 2002; Petes and Meyer, 2018). Here, we primarily focus on the subsection of science policy within the U.S. federal legislative branch, i.e., the U.S. House of Representatives and the U.S. Senate, as this offers one practical and specific avenue for engagement. In the United States, the House has 435 representatives who represent their congressional district for 2-year terms and the Senate consists of 100 senators (two per state) elected for 6-year terms. Any of these 535 members may propose or introduce a bill. The member of Congress that proposes a bill becomes the primary "sponsor," but an unlimited number of fellow members can lend support by becoming "cosponsors". Bills go through many steps prior to becoming law (Figure 1). After proposal, bills are sent to committees (20 in the House,
16 in the Senate) and then subcommittees, with numerous opportunities for revisions and votes. Due to the many steps in this complex process, most introduced bills do not become law. For example, in the 115th congress (January 2017-January 2019), only 867 of 13,556 bills and resolutions were brought to a vote. In total, only $3 \%$ of bills and $6 \%$ of resolutions were adopted.

To engage in the legislative process, scientists can research and focus on actions within committees and subcommittees of broad relevance to science (Figure 2). For example, marine biologists may be interested in tracking legislation and activity of the Senate subcommittee on Fisheries, Water, and Wildlife or the House subcommittee on Water, Oceans, and Wildlife. To track votes, hearings, and mark-ups within these subcommittees, researchers can sign up for email alerts on govtrack.us. See the Supplementary Material for additional resources for tracking science policy news.

Typically, bills are only brought to public attention at the time of Senate or House votes, which is toward the end of the legislative process. By tracking committee action, informed scientists can engage with legislators and show support or opposition for a bill throughout the process. Importantly, policymakers will sometimes publicly solicit information, giving scientists the opportunity to offer input on a bill. Tracking a bill through congress can thus provide scientists with a more direct impact on its success or failure. Scientists can also engage with their senators or representatives by asking for specific action (e.g., cosponsoring or supporting a bill) on legislation. See "Step 4 " for details on effective communication with members of Congress. Although these steps are specific to science policy within the U.S. federal government, we note this strategy of investigating pathways of legislation is generally useful for initiating engagement in science policy.

\section{STEP 2: UNDERSTAND HOW SCIENCE IS FUNDED}

To better advocate for continued government-supported research, scientists should learn how federal agencies that support their research (e.g., National Science Foundation, National Institutes of Health, the Department of Defense) are funded. Briefly, the federal budget is divided into mandatory expenses (e.g., Social Security, Medicare, Medicaid, interest on the national debt) and discretionary spending (Figure 3). Discretionary spending is further divided into defense and nondefense spending. Scientific research is primarily sponsored by the latter, in non-defense discretionary (NDD) spending, which accounts for approximately $15 \%$ of the total federal budget. NDD funding, which encompasses "general science and basic research" and "space and other technology" also includes many other areas (e.g., education, veterans' benefits, health, transportation; Figure 3). General science is thus only a small portion of this NDD spending. For example, in fiscal year 2018, spending in general science, basic research, and space technology totaled $\$ 31.4$ billion or $4.9 \%$ of NDD funding ( $\$ 638.9$ billion) and $0.76 \%$ of total federal spending ( $\$ 4.1$ trillion). 


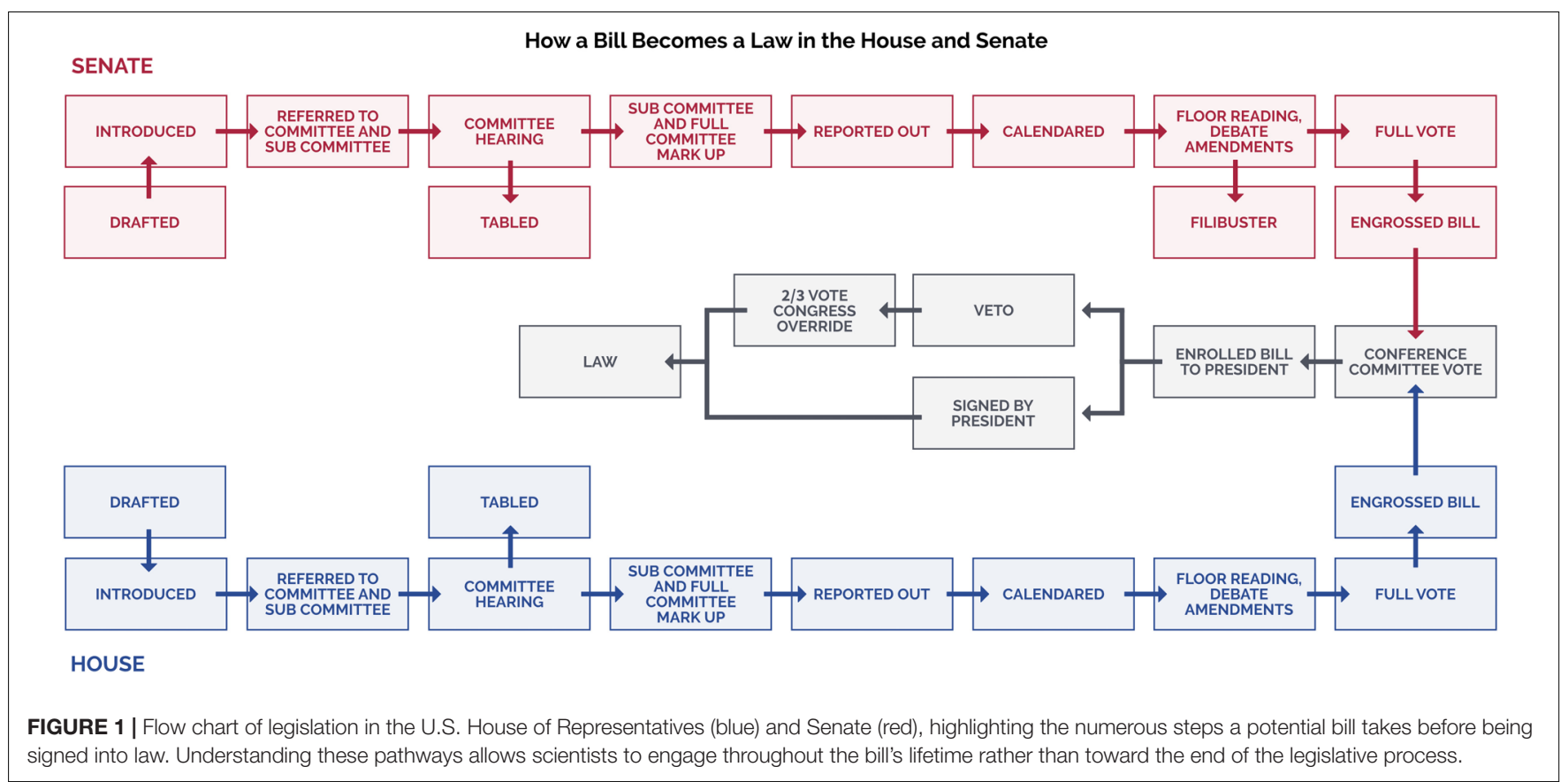

Each year Congress must pass a suite of appropriations bills that set these NDD spending outcomes. Generally, this process occurs annually in Spring, but in recent years, the budget process has been extended with continuing resolutions, or temporary measures that provide short-term funding to avoid a government shutdown. Due to this dynamic nature of appropriations decisions, we recommend subscribing to newsletter services or tracking appropriations committees on govtrack.us directly for notifications on important actions. Other organizations like the National Oceanic and Atmospheric Administration (NOAA) and the American Institute of Physics (AIP) also offer useful, interactive budget trackers on their websites (see Supplementary Material). Before these decisions are made, scientists can contact their legislators and advocate for increased NDD spending. This is especially impactful if your house representative and/or senators are members of the House or Senate appropriations committees. In addition to advocating general science funding, scientists can advocate for agencyspecific funding increases. Generally, agencies require at least $\sim 3-5 \%$ annual funding increases to account for inflation and growth. This target therefore provides a baseline for requests to policymakers when discussing appropriations goals.

\section{STEP 3: PRACTICE COMMUNICATION SKILLS}

Scientists lacking experience communicating their research in plain language to a policymaker audience should seek opportunities to develop their communication skills. Many universities have communication offices that connect students and employees with various local and regional news organizations, provide workshops on communicating research, and offer various outreach programs. While summarizing scientific communication opportunities is outside the scope of our objectives, we emphasize that developing communication skills to broad audiences is essential for effective science policy discussions.

Specifically, we recommend creating a "one-page document" or "one-pager" when communicating with policymakers. These documents are brief summaries of scientific research and relevant requests. They are useful for building relationships with congressional staffers and help prioritize conversations with policymakers. Effective one-pagers tell a concise story by offering an explanation of a research topic, establishing the importance of the topic, its relevance to policy at the local, state, or federal level, and clearly outlining the action (if any) you would like the office to take (see section "Step 5: Schedule a Meeting With Policymakers" for more details). See Supplementary Material for more details on crafting an effective one-pager.

For graduate students or early career researchers who are motivated to gain hands-on experience communicating with policymakers and are considering careers in science policy, there are numerous science policy fellowships. See the Supplementary Material for a compiled list of fellowships that provide short-term (typically 12 months) appointments in various facets of science policy and communication.

\section{STEP 4: FIND YOUR ELECTED OFFICIALS}

Communicating with appropriate government officials and policymakers, relative to the scope and focus of your research expertise, is necessary for effective participation in science policy. If your topic of interest relates specifically to your 


\section{Committees and Subcommittees Relevant to Science \\ HOUSE \\ SENATE}
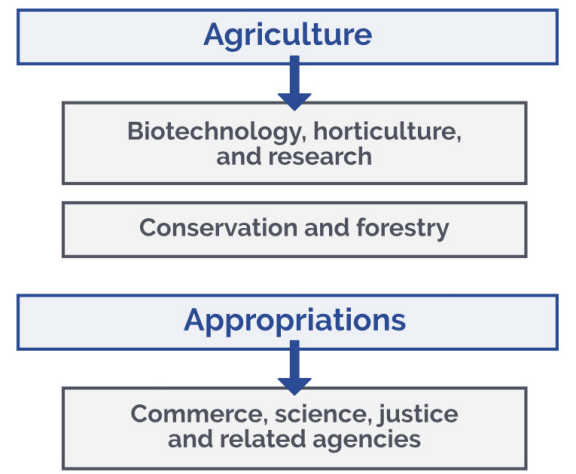

Energy, water, development, and related agencies

Interior, environment, and related agencies
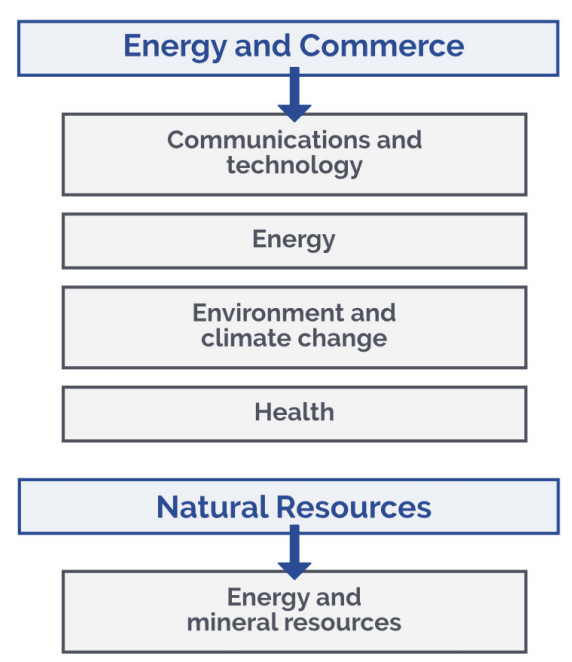

National parks, forests and public lands

Water, oceans, and wildlife

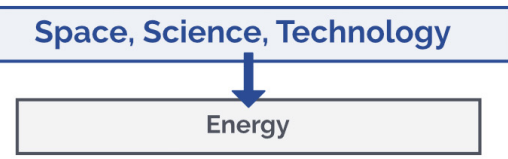

Environment

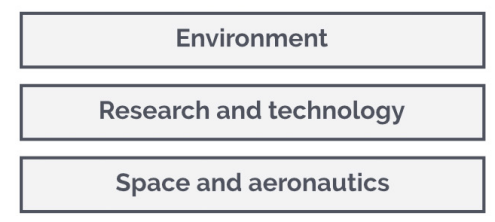

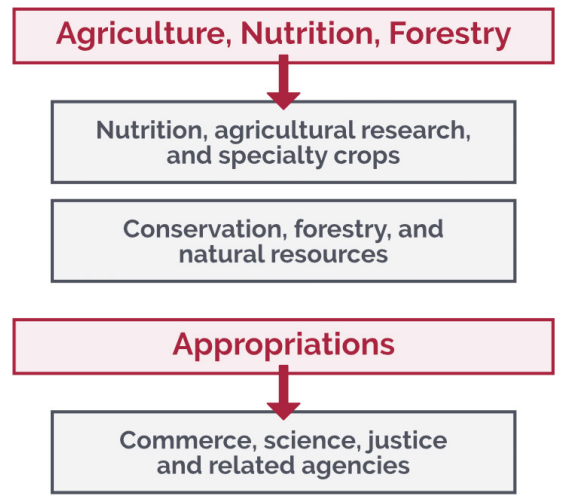

Department of the interior, environment, and related agencies

Energy and water development

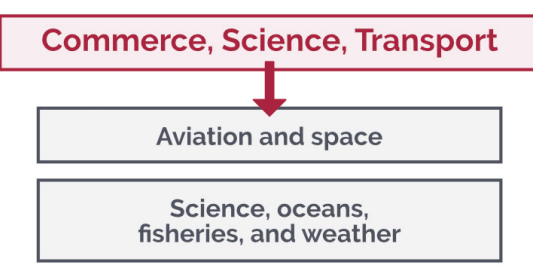

Communication, technology, innovation, and the internet

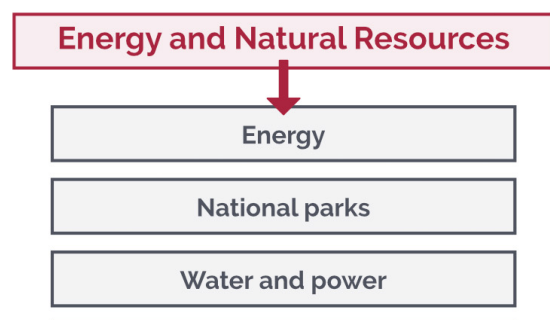

Public lands, forests, and mining

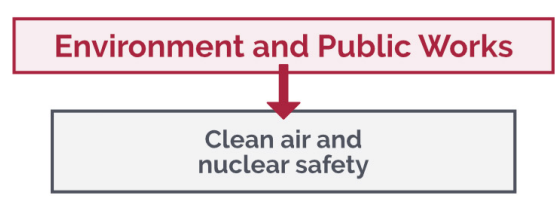

Fisheries, water, and wildlife

FIGURE 2 | Current 2019 standing committees in the U.S. House of Representatives (blue) and Senate (red) with the highest relevance to science and science policy. Within each committee, numerous subcommittees exist with narrower scopes within science and engineering. We recommend by identifying one to three relevant subcommittees and tracking their actions directly on govtrack.us. 


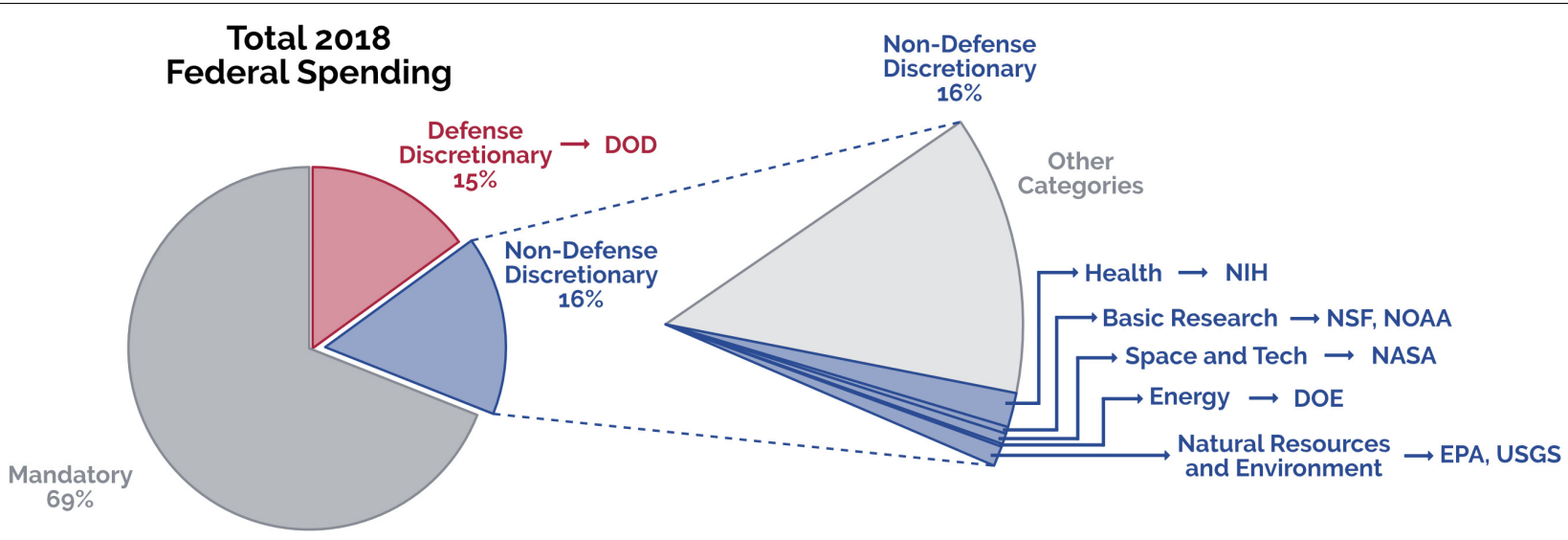

FIGURE 3 | Proportions of fiscal year 2018 federal spending, highlighting scientific research and agencies nested within the overall budget. Government spending is broadly divided between mandatory (gray) and discretionary expenses (blue and red). Mandatory expenses are largely determined by the White House Office of Management and Budget (OMB) and are inflexible. Appropriations bills are required to set discretionary spending. Non-defense discretionary spending (blue) is more flexible and supports a large portion of scientific research within the United States and is decided by appropriations bills in Congress. Arrows indicate some of the agencies that are funded through each category; Department of Defense (DOD), National Institute of Health (NIH), National Science Foundation (NSF), National Oceanic and Atmospheric Administration (NOAA), National Aeronautics and Space Administration (NASA), Environmental Protection Agency (EPA), United States Geologic Survey (USGC).

congressional district, identify your representative ${ }^{1}$ and senator ${ }^{2}$. Using personal congressional websites and govtrack.us, find their committee assignments and track bills that they have sponsored and co-sponsored to examine their positions and involvement on science related issues. Outside Congress, research agencies and government officials (e.g., staff in the mayor's office, city or town council members) in the community, especially when there are local policy issues relevant to your science expertise. For example, if you are interested in coastal resilience to climate change, research whether your city or state has a climate action plan.

\section{STEP 5: SCHEDULE A MEETING WITH POLICYMAKERS}

For scientists beginning to engage in policy, a streamlined way to navigate congressional meetings is to attend an official congressional visit day through an organization. These are days dedicated to specific issues on Capitol Hill (e.g., Climate Science Day, Ocean Week, or Geosciences Congressional Visits Day). Some scientific organizations (e.g., the American Geophysical Union, the American Institute of Biological Sciences) organize and provide funding for scientists to participate in these science advocacy days on Capitol Hill.

If attending a congressional visit day is not possible, universities often have a government relations office that can facilitate meetings with local policymakers. Partnering with scientific organizations or university offices that regularly communicate with congressional offices will lower the entry barrier to engage in science policy and will provide support on how to successfully navigate congressional meetings. However, if

${ }^{1}$ www.whoismyrepresentative.com

${ }^{2}$ https://www.senate.gov/senators/ these avenues are not available, many legislators have "Request a Meeting" tabs on their websites, which include contact information for direct requests to meet with staff members. Be aware that the process of scheduling a meeting may take several months and is dependent on the congressional calendar.

Prior to scheduling, research the policymaker of interest. Visit their official website and govtrack.us (see Step 1) to identify which bills the legislator has sponsored and co-sponsored. Research their prior support for science and the specific request you are planning to discuss. Having clear, realistic objectives is crucial for effective meetings. Congressional staffers are extremely timelimited and will inquire about the purpose of your visit prior to scheduling a meeting.

\section{STEP 6: NAVIGATE MEETINGS WITH POLICYMAKERS}

Congressional staffers meet daily with many people, so at the beginning of the meeting introduce yourself clearly and try to make personal and local connections. If applicable, thank the office for a recent action, such as sponsoring a bill related to your topic of interest. If discussing your research, ensure that you relate it to a broader topic of relevance to the district and policymaker, and share how government funding has directly supported your research. Be prepared with "asks," or tangible actions for the office. Asks can be general (e.g., advocating for increased science funding; see section "Step 1: Learn How Science Policy Is Enacted") or specific (e.g., related to a particular issue or piece of legislation). If appropriate, ask the legislator to consider signing, cosponsoring, or sponsoring a piece of legislation, or consider drafting new legislation.

Although it is recommended you are prepared with concrete "asks" for the office, leave room for a two-way dialog with the staff 
member. Many meetings are dominated by the visitors speaking, but listening is critical for building a relationship. Ask about science-related issues that are most important to their office and how your expertise may be helpful to the staffer.

At the end of the meeting, leave your contact information and one pager with the office (see Step 3). Within a few days of your meeting, follow up with an email to thank the office. At this time, it is useful to attach an electronic version of the one pager and a recent journal or news article relevant to your discussion.

\section{STEP 7: ENGAGE IN SCIENCE POLICY AT CONFERENCES}

Conferences are excellent opportunities to engage with policymakers, managers, and scientists with common interests on bridging the science policy divide. Meetings, such as those organized by the National Council for Science and the Environment and the National Marine Sanctuary foundation, are policy specific. Further, certain universities send delegations to international policy meetings and/or can provide financial support for students and researchers to attend policy meetings. However, for some researchers, especially students, attending a policy conference may not be feasible without support of their advisor. Advisors may be unwilling or unable to provide support for students to attend workshops or conferences that do not directly support their research. If financial constraints are the primary barrier, consider advocating for small departmental travel grants to cover the costs (see Step 9 for other ideas on increasing institutional support).

If attending a policy conference is not possible, take advantage of policy-related opportunities at larger researchfocused conferences. There are often sessions, town halls, and workshops dedicated to education, management, and policy. Certain conferences (e.g., Ocean Sciences Meeting, American Geophysical Union Meetings) also allow researchers to submit two abstracts if one focuses on education or policy. Taking advantage of these opportunities (see Supplementary Material for further details) enriches both the individual scientists and the university, as it demonstrates active connections between research, policy, and communicating science to a larger community.

\section{STEP 8: PUBLISH POLICY BRIEFS AND OPEN-ACCESS}

There are multiple barriers to disseminating scientific results to policymakers. Scientists typically present their research findings at conferences and through publication in academic journals. Managers and policymakers often lack access to scientific journal articles, which contributes to the science policy divide (Edwards, 2004). To make articles more accessible to the general public, scientists are increasingly publishing "openaccess" papers, which are free to all readers. However, authors are responsible for covering the additional fees associated with publishing open-access articles, which are prohibitive for some researchers. Further, even when publications are available to policymakers, papers may be written in a technical manner, rendering the findings less accessible to many policymakers and management agencies.

In addition to publishing in open-access journals, scientists can make their research more accessible to policymakers by publishing a "plain-language summary" alongside manuscripts that summarize the findings for a general audience. Some journals (e.g., all journals by the American Geophysical Union) provide this option to authors. Another example of this approach is from intergovernmental organizations, such as the Intergovernmental Panel on Climate Change (IPCC), which publishes both a long technical report on climate change science and a short policy brief that highlights the major outcomes of the technical report. Scientists can seek out journals that have plainlanguage summaries or suggest them to editors in other journals. They can also write policy briefs or plain-language summaries to accompany each publication and send those summaries to policymakers, post them to social media accounts, or include them on personal and/or lab websites.

\section{STEP 9: BRING SCIENCE POLICY TO YOUR INSTITUTION}

The outlined steps have thus far primarily focused on individual actions, but engaging peers from your university or scientific community can be impactful for effective policy discussions. Universities can play an important role in building programs and courses that provide students with experiences that link science, policy, and society (Petes and Meyer, 2018). At the departmental level, advocate for inviting policy-focused individuals to departmental seminars. If there are alumni from your institution that have entered policy careers, invite them for a seminar or panel discussion. It may also be possible to invite a staffer from a local congressional or state senator's office for a special seminar on a timely policy issue. Reach out to the government relations office at your university to inquire about this possibility. Through their office, it may be possible to invite local policy makers and their staff to your lab, or department, for a tour or special seminar.

To build a science policy community at your institution, consider founding or joining a club. The club can provide a means to host speakers and science policy events at your university. For example, when relevant legislation is introduced, host a postcard night or town hall discussion. The club can also organize group trips to Capitol Hill or the local office of senators or representatives. These collective actions can bridge science and policy and lower the barrier for early career researchers to engage in policy efforts.

Lastly, these actions are not possible without institutional support. It is critical that faculty advisors, departments, and universities support early career researchers interested in policy engagement. Professors also need institutional support to engage in policy initiatives without concern of stalling progress toward research, publications, tenure, or promotion. To bridge the divide between research and policy, these efforts should be viewed as a complement to research and outreach efforts. 


\section{STEP 10: ACTIVATE THE COMMUNITY}

From a science policy perspective, researchers can use outreach efforts to engage on issues that are particularly relevant to a given community (e.g., climate resiliency, plastic pollution, water quality). Elected officials are chosen to represent their constituents. When constituents are passionate and particularly vocal about an issue, legislators are more likely to pay attention. Through actions like creating citizen science projects, we can engage the public in science, increase awareness about certain issues (Bonney et al., 2016), and potentially change attitudes or behaviors. Ultimately, public opinion is important for shaping policy outcomes and building support for legislation.

Scientists interested in policy should also attend community events, even when they are unrelated to their policy topics of interest. For example, find the congressional calendar to see when policymakers are home in their district, and attend city council or town hall meetings. Attending community events will provide perspective on issues community members are most engaged and passionate about. Outreach ultimately benefits scientists, institutions, and the surrounding community. Strengthening connections between research and local communities can help build public trust in science and support for federally funded science programs from the general public. While these efforts are more indirect and have a longer-term focus, building relationships in the community is an effective strategy for gaining awareness and eventual support for specific policy actions.

\section{CONCLUSION}

As scientists are increasingly inclined to engage with policymakers or pursue policy-related career paths (Miller, 2009; Petes and Meyer, 2018), guidance is needed on how scientists can effectively offer knowledge and expertise to guide policy. We highlighted 10 tangible and actionable steps that we hope will provide guidance for researchers on how to begin. While we outlined discrete steps, we emphasize that bridging the gaps between science and policy requires continued engagement that goes well beyond these actions. Continued engagement requires building relationships and trust between the scientific community and different stakeholders, which is built over time, with considerable effort and collaboration (Gluckman, 2014).

We focused on federal policy in the United States, reflecting our personal experiences engaging in science policy. However, the actions we proposed centered on learning how policy is

\section{REFERENCES}

Baron, N. (2016). So you want to change the world? Nat. News 540:517. doi: $10.1038 / 540517 \mathrm{a}$

Bertuol-Garcia, D., Morsello, C. N., El-Hani, C., and Pardini, R. (2018). A conceptual framework for understanding the perspectives on the causes of the science-practice gap in ecology and conservation. Biol. Rev. 93, 1032-1055. doi: $10.1111 /$ brv.12385

Besley, J. C., and Nisbet, M. (2013). How scientists view the public, the media and the political process. Public Understand. Sci. 22, 644-659. doi: 10.1177/ 0963662511418743 enacted, how to communicate and meet with policymakers, and make research findings more accessible. These principles are broadly applicable to global efforts, as they create a foundation for researchers to engage with the policy community. While the details of how to engage likely varies between countries with different government structures, we hope this guide provides a useful framework that can be adapted and modified for researchers at the science policy interface outside of the United States.

\section{AUTHOR CONTRIBUTIONS}

EH developed the concept for this manuscript and contributed to the development of each section. AP designed figures and contributed to the development of each section. Writing and editing the manuscript was equally divided by EH and AP.

\section{FUNDING}

The American Geophysical Union's "Voices for Science" program paid open-access fees for the publication of this article.

\section{ACKNOWLEDGMENTS}

We would like to thank the American Geophysical Union (AGU) and their Voices for Science program, of which both authors are 2019-2020 fellows. We especially thank Elizabeth Landau and Brittany Webster of AGU for their continued support and critical reviews of this manuscript, and Dr. Marika Schulhof for feedback on early drafts of the manuscript. Lastly, we thank our institutions, the California Institute of Technology and Scripps Institution of Oceanography, their government relations office, and our advisors, Dr. Alex Sessions (California Institute of Technology) and Dr. Anela Choy (Scripps Institution of Oceanography) for supporting our participation in science policy efforts and the Voices for Science Program.

\section{SUPPLEMENTARY MATERIAL}

The Supplementary Material for this article can be found online at: https://www.frontiersin.org/articles/10.3389/fmars. 2020.00409/full\#supplementary-material

Bonney, R., Phillips, T. B., Ballard, H. L., and Enck, J. W. (2016). Can citizen science enhance public understanding of science? Public Understand. Sci. 25, 2-16. doi: 10.1177/0963662515607406

Edwards, M. (2004). Social Science Research and Public Policy: Narrowing the Divide. Canberra: Academy of the Social Sciences in Australia.

Etsy, D. C., and Ivanova, M. H. (2002). Global Environmental Governance: Options \& Opportunities. New Haven, CT: Yale University.

Gluckman, P. (2014). Policy: the art of science advice to government. Nat. News 507:163. doi: 10.1038/507163a

Hutchings, J. A., and Stenseth, N. C. (2016). Communication of science advice to government. Trends Ecol. Evol. 1, 7-11. doi: 10.1016/j.tree.2015.10.008 
Miller, N. (2009). Uncertain science - uncertain politics. Environ. Polit. 8, 131-148. Petes, L. E., and Meyer, M. D. (2018). An ecologist's guide to careers in science policy advising. Front. Ecol. Environ. 16, 53-54. doi: 10.1002/fee. 1761

Poliakoff, E., and Webb, T. L. (2007). What factors predict scientists' intentions to participate in public engagement of science activities? Sci. Commun. 29, 242-263. doi: 10.1177/1075547007308009

Singh, G. G., Farjalla, V. F., Chen, B., Pelling, A. E., Ceyhan, E., Dominik, M., et al. (2019). Researcher engagement in policy deemed societally beneficial yet unrewarded. Front. Ecol. Environ. 17, 375-382. doi: 10.1002/fee. 2084

Singh, G. G., Tam, J., Sisk, T. D., Klain, S. C., Mach, M. E., Martone, R. G., et al. (2014). A more social science: barriers and incentives for scientists engaging in policy. Front. Ecol. Environ. 12, 161-166. doi: 10.1890/1 30011
Weingart, P. (1999). Scientific expertise and political accountability: paradoxes of science in politics. Sci. Public Policy 26, 151-161. doi: 10.3152/ 147154399781782437

Conflict of Interest: The authors declare that the research was conducted in the absence of any commercial or financial relationships that could be construed as a potential conflict of interest.

Copyright (c) 2020 Hetherington and Phillips. This is an open-access article distributed under the terms of the Creative Commons Attribution License (CC BY). The use, distribution or reproduction in other forums is permitted, provided the original author(s) and the copyright owner(s) are credited and that the original publication in this journal is cited, in accordance with accepted academic practice. No use, distribution or reproduction is permitted which does not comply with these terms. 